Araştırma Makalesi (Research Article)

Koray KAÇAN 1

Özhan $\mathrm{BOZ}^{2}$

\section{Ege Bölgesi Geleneksel ve Organik Bağ Alanlarında Yabancı Ot Tür Yoğunluk Rastlanma Sıklıklarının Belirlenmesi ve Karşılaştırılması}

\author{
The Comparison and Determination of The Weed Species in \\ Conventional and Organic Vineyards
} Müdürlüğü , 35040 İzmir/Türkiye

${ }^{2}$ Adnan Menderes Üniversitesi, Ziraat Fakültesi, Bitki Koruma Bölümü, 09100 İzmir /Türkiye

e-posta: koraykacan@gmail.com

\section{Anahtar Sözcükler:}

Bağ, rastlanma sıklığı, yabancı ot, yoğunluk

\section{Key Words:}

Vineyards, frequency,weed, density
Alını̧ (Received): 31.12.2014 Kabul tarihi (Accepted): 31.03.2015

\section{ÖZET}

M

anisa ili geleneksel ve organik üzüm üretimi yapılan bağlarda sorun olan yabancı ot türleri yoğunluk ve rastlanma sıklıklarının belirlenmesi amacıyla, 48 organik 76 geleneksel bağ alanında 2009-2011 yıllarında survey gerçekleştirilmiştir. Geleneksel bağ alanlarında kış döneminde 10 yaz döneminde ise 9 yabancı ot türü saptanmıştır. Kış döneminde sıra arasında rastlanma sıklığı en yüksek olan tür Stellaria media (L.) Vill. (\% 47.4) olmuştur. Diğer türlerin rastlanma sıklıkları \% 8.2 ile 42.3 arasında değişmiştir. Sıra üzerinde ise Hordeum murinum L. (\% 42.8) en fazla rastlanma sıklığını sahip tür olmuştur. Yaz döneminde sıra arasında ve sıra üzerinde Cynodon dactylon (L.) Pers. (\% 51.3-64.8) rastlanma sıklığı en yüksek tür olmuştur. Sıra arasında diğer türlerin rastlanma sıklıkları \% 5.5-46.7 arasında değişmiştir. Sıra üzerinde ise diğer türler \% 9.8-52.3 arasında rastlanılmıştır. Organik bağlarda kış döneminde 24 yabancı ot türü belirlenmiştir. Sıra arasında Stellaria media (L.) Vill. (\% 56.0) rastlanma sıklığı en yüksek tür olmuştur. Sıra üzerinde ise; Matricaria chamomilla L. (\% 54.3) en fazla rastlanan tür olmuştur. Organik bağlarda yaz dönemi 13 tür, belirlenirken, sıra arasında ve sıra üzerinde Cynadon dactylon (L.) Pers. (\% 64.8 - \%70.1) rastlanma sıklığı en yüksek tür olarak bulunmuştur.

\section{ABSTRACT}

This, study was carried out during 2009-2011 in Manisa. The aim of this study was to found out species, their density and frequency of weeds in the conventional and organic vineyards. Weeds problem was surveyed in 76 conventional and 48 organic grape vineyard production fields. In the conventionally grown vineyards, 10 weed species were identified in summer period and nine weed species during the winter. According to the results of survey, they indicated that Stellaria media (L.) Vill. (47.4\%) was the highest frequency in conventional vineyards during the winter in inter-row. The frequency of occurrence of other weed species ranged from $8.2 \%$ to $42.3 \%$. In intra-row of conventional vineyards during the winter period, Hordeum murinum L. (42.8\%) was found in the highest frequency. In other hand, Cynadon dactylon (L.) Pers. (51.3\% to 64.8\%) was found the highest frequency in inter row and intra row. In organic vineyards, 24 weeds species were identified in winter period. Stellaria media (L.) Vill. $(56.0 \%)$ was the highest frequency. Matricaria chamomilla L. (54.3\%) had the highest frequency in intra-row. In 13 species determined in organic vineyard in the summer, Cynadon dactylon (L.) Pers. $(64.8 \%$ to $70.1 \%)$ was the highest frequency in intra-row and inter row. 


\section{GíRiş}

Türkiye, dünya ülkeleri arasında bağ alanı ve yaş üzüm üretimi yönünden 6. sırada yer almaktadır (Anonim, 2013a). Üretilen 4.296 .000 ton yaş üzümün yaklaşık \% 25'i sofralık olarak tüketilirken, \% 17.5'i çekirdeksiz kuru üzüm ve \% 15'i çekirdekli kuru üzüm olarak değerlendirilmektedir. Türkiye üzüm ihracatı ile ülke ekonomisi için önemli bir gelir kaynağını oluşturmaktadır. Bölgeler arasında ise 1,381,864 da dikim alanı, 2.094.731 ton üretimi ile Türkiye 'de Ege Bölgesi ilk sırayı almaktadır (Anonim, 2013b). Türkiye bağcılığı iller bazında değerlendirildiğinde, hem alan (738.226 da) hem de üzüm üretimi (1.513.540 ton) yönünden Manisa en ön sırada gelir. (Anonim, 2013b).

Bağcılıkta ürünü etkileyen etmenler arasında yabancı otların önemli bir yeri vardır. Bunlar direkt rekabete girerek zararlı oldukları gibi birçok hastalık etmeni ve zararlılara da konukçuluk ederek dolaylı yollarla da ürün azalmasına neden olurlar. Bağlarda yabancı otların direkt neden olduğu verim kaybının \% 10,1 olduğu kaydedilmektedir (Cramer, 1967). Özellikle su sıkıntısının yaşanmaya başladığı dünyamızda, yabancı otlar asmanın suyuna ortak olarak bitkileri su stresine sokmaktadır.

Bağlarda görülen bazı yabancı otlardan, Cirsium arvense'nin topraktan N, P, K alımının yüksek olduğu bildirilmektedir (Farkhadi, 1968). Yine Sonchus arvensisin kök salgılarının asma kök gelişimini engellediği saptanmıştır (Racz ve Siaba, 1971).

Mücadelede; yabancı ot türlerinin belirlenmesi, yoğunluk ve rastlanma sıklıklarının bilinmesi büyük önem taşımaktadır. Bu çalışmanın da amacı Manisa ili organik ve geleneksel bağ alanlarında yabancı ot tür, yoğunluk ve rastlanma sıklıklarının belirlenmesidir. Literatüre bakıldığında, Uluğ (1989)'un Manisa ili bağlarında yabancı otların tür ve rastlanma sıklıklarının saptanmasına ilişkin yapmış olduğu bir çalışma dışında bir yayına rastlanmamıştır.

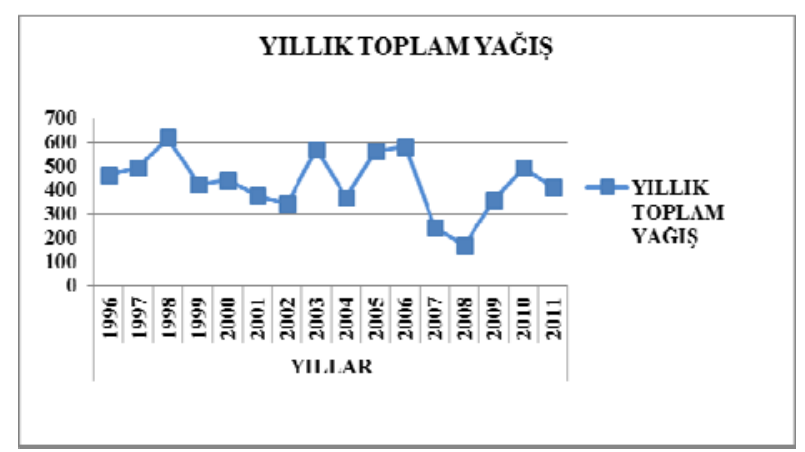

Şekil 1.Yıllara göre ortalama yağış miktarları

Figure 1. The Average rainfalls according to the years
Bilindiği gibi yapılan tarım uygulamaları, mücadele yolları yabancı ot florasını büyük ölçüde değiştirmektedir. Yirmi beş yılı aşkın bir sürede bu floranın değişmesi de doğaldır. Bu nedenle önemli bir bağ alanı olan Manisa ilinde yabancı ot florasının tespiti büyük önem taşımaktadır. Bu gerekçeyle yapılan çalışma özgün olma niteliği taşımaktadır. Kaldı ki Türkiye de organik tarım üretimine 1984-1985 yıllarında başlanmıştır (Aksoy, 1999). Bu bağlamda organik tarım yapılan bağ alanlarında yabancı ot florasının belirlenmesine ilişkinde hiçbir çalışmaya rastlanılmamıştır. Bu neden bu çalışma yine özgün bir nitelik taşımaktadır. Elde edilen sonuçların geleneksel ve organik tarım alanlarındaki yabancı ot florasının karşılaştırılması da amaçlanmıştır. Çalışamadan elde edilen sonuçlar gerek organik gerekse de geleneksel bağcılıkta yabancı ot sorununu güncel olarak ortaya koyması ve mücadele yollarının belirlenmesi açısından büyük önem taşıyacaktır.

\section{MATERYAL}

Çalışmamızın ana materyalini Manisa ili bağ alanlarında bulunan yabancı otlar, surveyde kullanılan çerçeveler, herbaryum malzemeleri oluşturmaktadır.

Manisa ilinin iklim özellikleri; Ege kıyılarına göre Manisa ili iklimi daha sert olup, yazları sıcak ve kurak, kışları ılık ve yağışlı geçmektedir. Dağlık olan kuzey ve kuzeydoğu bölgesinde yazlar serin ve kışlar soğuk geçmektedir. En soğuk aylar Ocak ve Şubat olup, en çok yağış Aralıkta ve en az yağış Temmuz ve Ağustos aylarındadır. Senelik ortalama yağış miktarı metrekarede $750 \mathrm{~mm}^{\prime}$ dir. Sıfır derecenin altındaki gün sayısı 25'i geçmemektedir. Mevsimsel sıcaklık ortalamaları ise $6.7^{\circ} \mathrm{C}$ ile $27.6^{\circ} \mathrm{C}$ arasında seyretmektedir. Yıllara göre yağış ve sıcaklık değişimleri Şekil 1 ve Şekil 2 'de görülmektedir (Anonim, 2014). İklim yabancı otların çıkışını ve yoğunluğunu etkilemesi açısından bu bölümde Manisa ili yıllık toplam yağış ve sıcaklık değerleri verilmiştir.

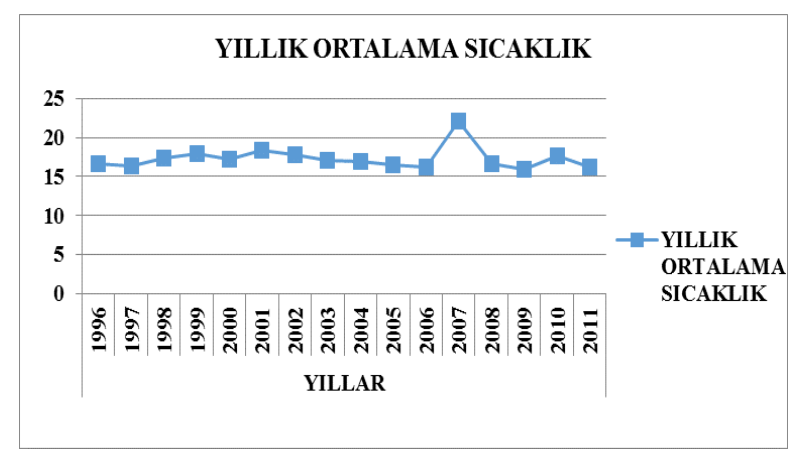

Şekil 1.Yıllara göre ortalama sıcaklık miktarları

Figure 2. The Average temperatures according to the years 
Manisa ilinin arazi ve toprak özellikleri; Manisa ili birçok bitki türünün yetişmesi için elverişli, meyilli düz, iyi drene olmuş, kolay işlenebilir, derin ve verimli arazilere sahiptir. Genel olarak toprak özellikleri farklılık gösterse de toprakların \% 22.19'u allüviyal, \%26.16'sı kolluviyal, \% 0.002'si kırmızımsı Akdeniz toprakları, \% 0.004'ü kireçsiz Kahverengi toprak özelliği taşımaktadır. Arazilerim eğimi \% 2' den daha düşük, arazilerin \% 48.76'sında toprak derin, kalanın da orta derindir. Bu arazilerin \% 50'sinde sulu tarım, \% 10' unda nadaslı kuru tarım yapılmaktadır (Anonim, 2011).

\section{YÖNTEM}

Bu çalışmada, Manisa il merkezi ve 8 ilçesinde geleneksel ve organik yetiştiricilik yapılan bağ alan- larında görülen yabancı ot türlerini belirlemek, yoğunluk ve kaplama alanlarını saptamak amacıyla surveyler yapılmıştır. Surveylerde örnekleme yapılan alanların belirlenmesinde Bora ve Karaca (1970)'dan yararlanılmıştır. Organik bağ alanları belirlenirken sözleşmeli organik yetiştiricilik yapılan üreticiler tercih edilmiştir.

Surveyler, 2009-2010 yıllarında hem kış (MartNisan) florasını hem da yaz (Haziran-Temmuz) florasını kapsayacak biçimde, çapa öncesi olarak 76 geleneksel, 48 adet organik üretim yapılan bağlarda gerçekleştirilmiştir. Çizelge 1'de survey yapılan ilçeler, değerlendirilen organik ve geleneksel bağ sayıları, ilçelere göre dağılımları ve toplamı görülmektedir.

Çizelge 1. Manisa ilinde survey yapılan bağ alanları ve örnekleme sayıları. Table 1. The number of vineyards and sampling conducted in Manisa

\begin{tabular}{|c|c|c|c|c|c|c|}
\hline ILÇELER & Bağ Alanı (da) & $\begin{array}{c}\text { Toplam Alandaki } \\
\text { Payı (\%) }\end{array}$ & $\begin{array}{l}\text { Geleneksel } \\
\text { Bağ Sayısı }\end{array}$ & $\begin{array}{c}\text { Survey Yapilan } \\
\text { Alan (da) }\end{array}$ & $\begin{array}{c}\text { Organik } \\
\text { Bağ Sayısı }\end{array}$ & $\begin{array}{c}\text { Survey Yapılan } \\
\text { Alan (da) }\end{array}$ \\
\hline 1. Merkez & 72000 & 14,58 & 11 & 92 & - & \\
\hline 2. Ahmetli & 39000 & 7,90 & 6 & 122 & 8 & 235 \\
\hline 3. Akhisar & 14250 & 2,88 & 2 & 32 & - & - \\
\hline 4. Alaşehir & 104500 & 21,17 & 16 & 364 & 14 & 286 \\
\hline 5. Gölmarmara & 10500 & 2,12 & 2 & 56 & 4 & 38 \\
\hline 6. Salihli & 91200 & 18,48 & 14 & 280 & 6 & 80 \\
\hline 7. Sarıgöl & 27200 & 5,52 & 4 & 68 & - & - \\
\hline 8. Saruhanlı & 61900 & 12,54 & 10 & 220 & 12 & 270 \\
\hline 9. Turgut/u & 73000 & 14,79 & 11 & 198 & 4 & 64 \\
\hline TOPLAM & 493550 & 100,00 & 76 & 1432 & 48 & 973 \\
\hline
\end{tabular}

Survey sırasında bağ alanının büyüklüğüne göre kullanılan çerçeve sayısı şu yönteme göre belirlenmiştir; $1 \mathrm{~m}^{2}$ 'lik çerçeve, 0-5 dekar için 5 kez, 5-10 da için $10,10-20$ da için 20 ve 20 dekardan büyük alanlar için 30 kez kullanımıştır. Kenar etkisinden kurtulmak için, kenarın 10-15 m içerisine girilerek tarlanın köşegenleri doğrultusunda tesadüfî olarak çerçeveler atılmış ve sayımlar yapılmıştır. Yoğunluk her bitki için $1 \mathrm{~m}^{2 \prime} \mathrm{e}$ düşen sayı olarak, rastlanma sıklığı yüzdesi (RS) ise her incelenen tarlada atılan çerçeve görülme sayısına göre yüzde olarak belirlenmiştir. Geniş yapraklı yabancı otlar belirlenirken tüm bitki olarak, dar yapraklı yaban$\mathrm{Cl}$ otlar ise sap olarak sayılmıştır. Tanınan türler kayda geçirilmiş, tanınmayan türler ise numaralandırılıp herbaryumu yapılarak laboratuvara getirilip Davis (1965-1988)'e göre teşhisleri yapılmıştır. Geleneksel ve organik bağ yetiştiriciliği yapılan bağ alanlarındaki yabancı otlar ayrı ayrı yabancı ot türleri, yoğunlukları (adet $/ \mathrm{m}^{2}$ ) ve rastlanma sıklıkları belirlenmiş ve karşılaştırılmıştır.

\section{BULGULAR}

Geleneksel bağ alanlarında saptanan yabancı ot türleri, yoğunlukları ve rastlanma sıklıkları

Manisa ilinde 76 geleneksel bağ alanında gerçekleştirilen survey sırasında rastlanma sıklığı \% 2'nin altında bulunan yabancı ot türleri çizelgeye dâhil edilmemiştir. Surveylerde kış ve yaz döneminde sıra arasında 16 sıra üzerinde 14 farklı yabancı ot türü saptanmıştır. Belirlenen yabancı ot türleri Çizelge 1 ve 2 'de verilmiştir. Yabancı otların rastlanma sıklığı aşağıda formülle hesaplanmıştır.

R:S: Rastlanma Sıklığı = Tarlada Atılan Çerçeve Sayısı - Yabancı Otun Görüldüğü Çerçeve SayıSı X 100

Tarlada Atılan Toplam Çerçeve Sayısı 


\section{Geleneksel bağ alanlarında kış döneminde saptanan türler, yoğunlukları ve rastlanma sıklıkları}

Geleneksel bağlarda rastlanma sıklığı \% 2'nin üzerinde olan sıra arasında ve sıra üzerinde $8^{\prime}$ er adet olmak üzere 10 farklı kışlık yabancı türü belirlenmiştir. Kış döneminde sıra arasında rastlanma sıklığı en yüksek yabancı ot türü \% 47.4 rastlanma sıklığıyla Stellaria media L. olmuş; bunu sırasıyla Matricaria chamomilla L. (\% 42.3), Capsella bursa-pastoris (L.) Medik. (\% 42.0), Phalaris minor (L.) Retz., (\% 40.1), Convolvulus arvensis L. (\% 40.0), Hordeum murinum L. (\% 32.8), Lactuca serriola L. (\% 32.0) ve Papaver rhoeas L (\% 8.2) yabancı ot türleri takip etmiştir. Yabancı ot türlerinin sıra arasında $\mathrm{m}^{2}$ 'deki yoğunluklarına bakıldığında; en yüksek yoğunluğa sahip olan yabancı ot türü olarak $11.8 \mathrm{bitki} / \mathrm{m}^{2}$ ile Convolvulus arvensis belirlenmiştir (Çizelge 2).

Sıra üzerindeki türlerin rastlanma sıklıkları incelendiğinde; \% 42.8 oranıla $H$. murinum en fazla rastlanan tür olmuştur. Surveyin yapıldığı geleneksel bağlarda sıra üzerinde yoğunluklara bakıldığında; en yüksek yoğunluğa sahip yabancı ot türü olarak 6.8 bitki/m² ile Conolvulus arvensis belirlenmiştir.

Çizelge 2. Manisa ili geleneksel bağlarda kış döneminde saptanan yabancı ot türleri, rastlanma sıklıkları ve yoğunlukları (2009-2010) Table 2. During winter period determined weed species and the frequency of occurrence and intensityin conventional vineyards in Manisa (2009-2010)

\begin{tabular}{lcccc}
\hline & \multicolumn{2}{c}{ SIRA ARASI } & \multicolumn{2}{c}{ SIRA ÜZERi } \\
\hline Yabancı Otlar & ${ }^{*}$ RS & Yoğunluk & ${ }^{* R S}$ & $\begin{array}{c}\text { Yoğunluk } \\
\text { Adet } / \mathbf{m}^{2}\end{array}$ \\
\hline Stellaria media & 47.4 & 5.2 & - & - \\
Matricaria chamomilla $L$. & 42.3 & 3.8 & 25.9 & 2.7 \\
Capsella bursa-pastoris & 42.0 & 2.4 & - & - \\
Phalaris minor & 40.1 & 4.1 & 30.2 & 4.3 \\
Convolvulus arvensis & 40.0 & 11.8 & 32.5 & 6.8 \\
Hordeum murinum & 32.8 & 7.4 & 42.8 & 4.2 \\
Lactuca serriola & 32.0 & 2.2 & 22.3 & 3.4 \\
Papaver rhoeas & 8.2 & 0.6 & 10.2 & 2.8 \\
Sonchus oleraceus & - & - & 17.2 & 0.4 \\
Sisymbrium officinale & - & - & 14.6 & 1.2 \\
\hline
\end{tabular}

${ }^{*} R S$; *Rastlanma Sıklı̆ıı; \% 2'nin altında bulunan yabancı ot türleri tabloya dahil edilmemiştir

Geleneksel bağ alanlarında yaz döneminde saptanan yabancı ot türleri, yoğunlukları ve rastlanma sıklıkları

Geleneksel bağ alanlarında yaz döneminde sıra arasında 8 ve sıra üzerinde 6 adet yabancı ot türü belirlenmiştir. (Çizelge 3). Sıra arasında rastlanma sıklığı bakımından Cynodon dactylon (L.) Pers. \% 51.3 oranıyla en fazla rastlanan tür olmuş, bunu Phragmites australis (L.) (Cav.) Trin. ex Steud. (\% 46.7), Cynanchum acutum L. (\% 38.8), Conyza canadensis L. (\% 34.6), Cyperus rotundus L. (\% 30.2), Seteria verticillata (L) P. Beauv. (\% 27.0), Xanthium strumarium L. (\% 22.6) ve Portulaca olerecea L. (\% 5.5) yabancı ot türleri izlemiştir. Geleneksel bağ alanlarında yaz döneminde sıra arasında saptanan yabancı otların yoğunluklarına bakıldığında; en yüksek yoğunluğa sahip olan yabancı ot türü $9.4 \mathrm{bitki} / \mathrm{m}^{2}$ ile $P$. australis olmuştur. Sıra üzerinde ise rastlanma sıklığı \% 2'nin üzerinde olan 6 adet yabancı ot türü saptanmıştır (Çizelge 3). Çizelge incelendiğinde; rastlanma sıklığı bakımından C. dactylon (\% 64.8) en fazla rastlanan yabancı ot türü olarak bulunmuştur. Sıra üzerindeki yoğunluklarına bakıldığında en yüksek yoğunluğa sahip yabancı tür $C$. dactylon $\left(17.6 \mathrm{bitki} / \mathrm{m}^{2}\right)$ dikkati çekmiştir (Çizelge 3). 
Çizelge 3. Manisa ili geleneksel bağ alanlarında yaz döneminde saptanan yabancı ot türleri, rastlanma sıklıkları ve yoğunlukları (2009-2010) Table 3. During summer period determined weed species and the frequency of occurrence and intensityin conventional vineyards in Manisa (2009-2010)

\begin{tabular}{|c|c|c|c|c|}
\hline \multirow[b]{2}{*}{ Yabancı Otlar } & \multicolumn{2}{|c|}{ SIRA ARASI } & \multicolumn{2}{|c|}{ SIRA ÜZERI } \\
\hline & ${ }^{*} R S(\%)$ & $\begin{array}{l}\text { Yoğunluk } \\
\left(\text { Adet } / m^{2}\right)\end{array}$ & ${ }^{*} R S(\%)$ & $\begin{array}{l}\text { Yoğunluk } \\
\left(\text { Adet } / m^{2}\right)\end{array}$ \\
\hline Cynadon dactylon & 51.3 & 8.6 & 64.8 & 17.6 \\
\hline Phragmites, australis & 46.7 & 9.4 & 48.4 & 12.6 \\
\hline Cynanchum acutum & 38.8 & 0.5 & 52.3 & 2.5 \\
\hline Conyza canadensis & 34.6 & 1.7 & - & - \\
\hline Cyperus rotundus & 30.2 & 5.8 & 28.7 & 10.6 \\
\hline Steria verticillata & 27.0 & 4.6 & 37.4 & 5.1 \\
\hline Xanthium strumarium & 22.6 & 3.6 & - & - \\
\hline Portulaca olerecea & 5.5 & 2.2 & - & - \\
\hline Chenepodium album & - & - & 9.8 & 4.6 \\
\hline
\end{tabular}

*RS; *Rastlanma Sıklığı;\% 2'nin altında bulunan yabancı ot türleri tabloya dahil edilmemiştir

\section{Organik bağ alanlarında saptanan yabancı ot türleri, yoğunlukları ve rastlanma sıklıkları}

Manisa ilinde 48 organik bağ alanında gerçekleştirilen surveyler sırasında kış ve yaz dönemlerinde sıra arasında 31 ve sıra üzerinde 24 tür belirlenmiştir. Belirlenen yabancı ot türleri, rastlanma sıklık ve yoğunlukları Çizelge 4'de verilmiştir.

\section{Organik bağ alanlarında kış döneminde saptanan yabancı ot türleri, yoğunlukları ve rastlanma sıklıkları}

Organik bağ alanlarındaki surveylerde kış döneminde belirlenen yabancı ot türleri, rastlanma sıklıkları ve yoğunlukları Çizelge 4.'de verilmiştir. Kış döneminde sıra arasında toplam 19 yabancı ot türü belirlenirken, sıra üzerinde 17 tür belirlenmiştir. Sıra arasında \% 56 rastlanma sıklığıyla ile $S$. media en fazla rastlanan tür olmuş ve bu türü Melilotus officinalis (\% 54.6), $M$. chamomilla (\% 48.2), P. minor (\% 44.4), C. bursapastoris (\% 42.3) yabancı ot türleri izlemiştir. Kış döneminde sıra arasında görülen türlerin yoğunlukları bakımından S. media (8.9 bitki $\left./ \mathrm{m}^{2}\right)$ birinci sırada yer almıştır. Diğer yabancı ot türleri 0.3-6.7 bitki $/ \mathrm{m}^{2}$ arasında yoğunluklarda belirlenmişlerdir.

Sıra üzerindeki kışlık yabancı otlar incelendiğinde yabancı ot türlerinden 17 adedi $\% 2$ ve üzeri rastlanma sıklığına sahip türlerden oluşmaktadır. Sıra üzerinde rastlanma sıklığı bakımından M. chamomilla (\% 54.3) en fazla rastlanan tür belirlenmiştir. Organik bağ alanlarında sıra üzerinde saptanan yabancı otların yoğunluklarına bakıldığında en yüksek yoğunluğa sahip olan yabancı ot türü olarak $H$. murinum (32.8 bitki $\left./ \mathrm{m}^{2}\right)$ belirlenmiştir (Çizelge 4).

Organik bağ alanlarında yaz döneminde saptanan yabancı ot türleri rastlanma sıklıkları ve yoğunlukları

Manisa ili Organik bağ alanlarında yaz döneminde belirlenen yabancı ot türleri rastlanma sıklıkları ve yoğunlukları Çizelge 5.'de verilmiştir. Yaz döneminde organik bağ alanlarında toplam 13 tür belirlenmiştir. Bunlardan sıra arasında 12 sıra üzerinde ise 7 yabancı ot türü saptanmıştır. Çizelge $5^{\prime}$ de görüldüğü gibi yaz döneminde sıra arasında rastlanma sıklığı bakımından C. dactylon (\% 64.8) en fazla rastlanan yabancı ot türü olmuştur. Bunu Amaranthus retroflexus L. (\% 52.4). P. australis (\% 46.4). C. canadensis (\% 42.8). P. olerecea (\% 32.2). C. rotundus (\% 30.3). S. verticillata (\% 27.3). $X$. strumarium (\% 18.6). Tribulus terrestris L. (\% 11.7). Sorghum halepense (L.) Pers. (\% 8.4). C. album (\% 6.2) ve Solanum nigrum L. (\% 2.1) türleri izlemiştir.

Sıra arasında rastlanan yabancı otların yoğunluklarına bakıldığında, en yüksek yoğunluğu sahip olan yabancı ot olarak $C$. dactylon $\left(13.4 \mathrm{bitki} / \mathrm{m}^{2}\right)$ olmuştur (Çizelge 5).

Manisa ili organik bağ alanlarında yaz döneminde sıra üzerinde rastlanan sıklığı en yüksek tür $C$. dactylon (\%70.1) olmuştur (Çizelge 5).

Sıra üzerindeki yabancı ot yoğunluklarına bakıldığında ise en yüksek yoğunluğu sahip olan yabancı ot türü olarak yine $C$. dactylon $\left(32.4 \mathrm{bitki} / \mathrm{m}^{2}\right)$ dikkat çekmiştir (Çizelge 5). 
Çizelge 4. Manisa ili organik bağ alanlarında kış döneminde saptanan yabancı ot türleri, rastlanma sıklıkları ve yoğunlukları (2009-2010). Table 4. Weed species determined in organic vineyard and their the frequency of occurrence and intensity during winter period in Manisa (2009-2010)

\begin{tabular}{|c|c|c|c|c|}
\hline \multirow[b]{3}{*}{ Yabancı Otlar } & \multirow{2}{*}{\multicolumn{2}{|c|}{ SIRA ARASI }} & \multirow{2}{*}{\multicolumn{2}{|c|}{ SIRA ÜZERI }} \\
\hline & & & & \\
\hline & ${ }^{*} R S(\%)$ & Yoğunluk adet/m² & *RS (\%) & Yoğunluk Adet $/ m^{2}$ \\
\hline Stellaria media & 56.0 & 8.9 & 32.4 & 12.8 \\
\hline Melilotus officinalis & 54.6 & 1.8 & - & - \\
\hline Matricaria. chamomilla & 48.2 & 5.8 & 54.3 & 6.1 \\
\hline Phalaris minor & 44.4 & 5.5 & 48.4 & 5.4 \\
\hline Capsella bursa-pastoris & 42.3 & 6.7 & 27.4 & 5.7 \\
\hline Convolvulus arvensis & 40.7 & 4.8 & 21.6 & 2.2 \\
\hline Malva neglecta & 26.2 & 0.6 & - & - \\
\hline Polygonum. aviculare & 25.1 & 6.5 & - & - \\
\hline Fumaria officinalis & 24.8 & 1.0 & 8.9 & 2.8 \\
\hline Hordeum murinum & - & - & 24.6 & 32.8 \\
\hline Lactuca serriola & 20.4 & 0.7 & 34.5 & 1.2 \\
\hline Papaver rhoeas & 20.0 & 2.4 & 30.7 & 3.4 \\
\hline Erodium cicutarium & 13.1 & 3.4 & 7.2 & 3.4 \\
\hline Inula viscosa & 11.2 & 0.6 & 8.6 & 0.6 \\
\hline Raphanus raphanistrum & 5.4 & 1.2 & 6.1 & 1.2 \\
\hline Calendula arvensis & 4.6 & 2.8 & - & - \\
\hline Poa annua & - & - & 25.4 & 2.3 \\
\hline Senecio vulgaris & 4.2 & 1.45 & - & - \\
\hline Sonchus oleraceus & - & - & 47.2 & 0.6 \\
\hline Sisymbrium officinale & - & - & 12.6 & 0.1 \\
\hline Urtica urens & 2.0 & 0.8 & - & - \\
\hline Veronica hederifolia & - & - & 28.2 & 3.8 \\
\hline Sinapis arvensis & 2.0 & 0.4 & 2.1 & 0.4 \\
\hline Rumex crispus & 2.0 & 0.3 & - & - \\
\hline
\end{tabular}

${ }^{*}$ RS; Rastlanma Sıklığı; \% 2'nin altında bulunan yabancı ot türleri tabloya dâhil edilmemiştir

Çizelge 5. Manisa ili organik bağ alanlarında yaz döneminde saptanan yabancı ot türleri, rastlanma sıklıkları ve yoğunlukları (2009-2010). Table 5. Weed species determined in organic vineyard and their the frequency of occurrence and intensity during summer period in Manisa (2009-2010)

\begin{tabular}{|c|c|c|c|c|}
\hline \multirow[b]{2}{*}{ Yabancı Otlar } & \multicolumn{2}{|c|}{ SIRA ARASI } & \multicolumn{2}{|c|}{ SIRA ÜZERi } \\
\hline & ${ }^{*}$ RS (\%) & Yoğunluk (Adet/m²) & *RS (\%) & Yoğunluk (Adet $/ \mathrm{m}^{2}$ ) \\
\hline Cynadon dactylon & 64.8 & 13.4 & 70.1 & 32.4 \\
\hline Amaranthus retroflexus & 52.4 & 11.2 & - & - \\
\hline Phragmites australis & 46.4 & 6.7 & 53.5 & 6.5 \\
\hline Conyza canadensis & 42.8 & 0.78 & - & - \\
\hline Portulaca. olerecea & 32.2 & 12.5 & - & - \\
\hline Cyperus rotundus & 30.3 & 8.4 & 26.5 & 3.4 \\
\hline Seteria verticillata & 27.3 & 7.6 & 50.4 & 8.7 \\
\hline Xanthium strumarium & 18.6 & 4.56 & - & - \\
\hline Tirribulus terrestris & 11.7 & 1.46 & - & - \\
\hline Sorghum halepense. & 8.4 & 2.55 & 8.4 & 2.5 \\
\hline Chenepodium album & 6.2 & 4.43 & 26.8 & 7.3 \\
\hline Solanum nigrum & 2.1 & 0.85 & - & - \\
\hline Cynanchum acutum & - & - & 62.4 & 2.4 \\
\hline
\end{tabular}

*RS; Rastlanma Sıklığı; \% 2'nin altında bulunan yabancı ot türleri tabloya dahil edilmemiştir. 


\section{TARTIŞMA ve SONUÇ}

Türkiye, bağclık için optimum koşullara sahip ülkelerden biri olup, dünya ülkeleri arasında bağ alanı ve yaş üzüm üretimi yönünden 6 . sırada yer almaktadır. En önemli çeşit olan Sultani çekirdeksiz üzüm, toplam üretiminin $\% 80$ 'nini oluşturmakta ve büyük çoğunluğu Avrupa ülkelerine ihraç edilmektedir (Anonim, 2013a; Anonim 2013b).

Yabancı otlar geleneksel ve organik tarımda önemli sorun olan etmenlerdir. Kültür bitkilerine verdikleri direkt ve indirekt (hastalık ve zararlılara konukçuluk) zarar ile önemli ürün kayıplarına neden olurlar. Ancak mücadeleye başlamadan, o alanın yabancı ot türlerinin, yoğunluk ve yaygınlık durumlarının belirlemesi, mücadele yönteminin seçim ve uygulanmasında büyük önem taşımaktadır. Manisa ilinde 76 geleneksel bağ alanında gerçekleştirilen incelemede, 19 yabancı ot türü saptanmıştır. Bu türlerin yer aldıkları familyalar Çizelge 6 'da görülmektedir.

Çizelge 6. Geleneksel ve Organik bağ üretim alanlarında saptanan yabancı ot türleri ve yer aldığı familyalar Table 6. The species and families determined in conventional and organic vineyards.

\begin{tabular}{|c|c|c|c|c|}
\hline Familyası & Yabanci Otlar & Türkçe Isimleri & Geleneksel* & Organik* \\
\hline Amaranthaceae & A. retroflexus & Horozibiği & - & + \\
\hline Asclepiadaceae & C. acutum & Sütlü sarmaşık & + & + \\
\hline Asteraceae & Cal. arvensis & Portakal nergisi & - & + \\
\hline " & C. canadensis & Pire otu & + & + \\
\hline$"$ & İ. arvensis & Andız otu & - & + \\
\hline$"$ & L. serriola & Yabani marul & + & + \\
\hline " & M. chamomilla & Hakiki papatya & + & + \\
\hline$"$ & S. vulgaris & Imam kavuğu & - & + \\
\hline$"$ & S. oleraceus & Eşek marulu & + & + \\
\hline$"$ & X. strumarium. & Domuz pıtră̆ı & + & + \\
\hline Brassicaceae & C. bursa-pastoris & Çobançantası & + & + \\
\hline " & R. raphanistrum & Yabani turp & - & + \\
\hline$"$ & S. arvensis & Yabani hardal & - & + \\
\hline " & S. officinale & Bülbülotu & + & + \\
\hline Caryophyllaceae & S. media & Kuş otu & + & + \\
\hline Chenopodiaceae & C. album & Sirken & + & + \\
\hline Convolvulaceae & Conv. arvensis & Tarla sarmaşığı & + & + \\
\hline Cyperaceae & C. roduntus & Topalak & + & + \\
\hline Fabaceae & M. officinalis & Kokulu sarıyonca & - & + \\
\hline Fumariaceae & F. officinalis & Hakiki Şahtere & - & + \\
\hline Geraniaceae & E. cicutarium & Dönbaba & - & + \\
\hline Malvaceae & M. neglecta & Ebegümeci & - & + \\
\hline Papaveraceae & P. rhoeas & Gelincik & + & + \\
\hline Poaceae & C. dactylon & Köpek dişi ayrığı & + & + \\
\hline " & P. minor & Küçük başaklı kuşyemi & + & + \\
\hline$"$ & P. australis & Kamış & + & + \\
\hline$"$ & P. annua & Tavşan bıyığı & - & + \\
\hline$"$ & H. murinum & Duvar arapası & + & + \\
\hline$"$ & S. verticillata & Yapışkan ot & + & + \\
\hline$"$ & S. halapense & Kanyaş & - & + \\
\hline \multirow{2}{*}{$\begin{array}{l}\text { Polygonaceae } \\
\text { " }\end{array}$} & P. aviculare & Çobandeğneği & - & + \\
\hline & R. crispus & KIvırcık labada & - & + \\
\hline Portulacaceae & P. olerecea & Semizotu & + & + \\
\hline Solanaceae & S. nigrum & Köpek üzümü & - & + \\
\hline Urticaceae & U. urens & Küçük ısırgan & - & + \\
\hline Zygophyllaceae & T. terrestris & Demir dikeni & - & + \\
\hline
\end{tabular}

* Artı işareti (+) yabancı otların varlığını eksi işareti (-) ise yok olduğunu göstermektedir. 
Bu çizelge'de görüldüğü gibi geleneksel bağlarda Poaceae ve Asteraceae familyalarından 5'er tür, Brassicaceae familyasından 2, Asclepiadaceae, Chenopodiaceae, Convolvulaceae, Cyperaceae, Papaveraceae, Portulacaceae famiyalarından ise birer tür yer almıştır (Çizelge 6).

Organik üretim yapılan bağ alanlarında ise tür zenginliği dikkat çekmiş, 48 organik bağda yapılan incelemede yazlık ve kışlık toplam 36 tür belirlenmiștir (Çizelge 6). Bunlardan 8 tür Asteraceae familyasından, 7 tür Poaceae, 4 tür Brassicaceae ve 2 tür Polygonaceae familyalarında yer almıştır. Polygonaceae, Amaranthaceae, Asclepiadaceae, Caryophyllaceae, Chenopodiaceae, Convolvulaceae, Cyperaceae, Fabaceae, Fumariaceae, Geraniaceae, Malvaceae, Papaveraceae, Poaceae, Portulacaceae, Solanaceae, Urticaceae, Zygophyllaceae familyalarında ise birer tür belirlenmiştir.

Daha önce eski yıllarda Fransa'da yapılan survey çalışmasında bağlarda 110 adet yabancı ot türü saptandığı ve bu türlerin \% 67'sini tohumlu bitkilerin oluşturduğu bildirilmektedir (Barralis ve Drouhard. 1969). Rusya' nın Kazakistan bağlarında yapılan flora çalışmaların da 32 familyaya ait 127 yabancı ot türü saptanmıştır (Sultanova. 1967). Bununla beraber ülkemizde Manisa İli bağ alanlarında yapılan survey çalışmasında; 36 familyadan oluşan yabancı otların \% 19'u Fabaceae. \% 15.4'ü Astereceae ve \% 13.4'ü Poaceae familyasından olduğu belirtilmektedir (Uluğ. 1989). Buna göre survey çalışmamızda belirlenen yabancı otlar daha önce yapılan bu çalışmalar ile karşılaştıııldığında yabancı ot tür sayısının azaldığı, geleneksel bağ yetiştiriciliği ile organik karşılaştırıldığında gelenekselde 19, organik'te 48 tür olduğu belirlenmiştir. Buna göre survey çalışmamızda belirlenen yabancı otlar daha önce yapılan bu çalışmalar ile karşılaştıııldığında yabancı ot tür ve yoğunluklarının değiştiği bazı yabancı ot türlerinin survey alanında bulunmadığı ve bazı yabancı ot türlerinin dominant hale geldiği görülmektedir. Bunun nedeni olarak sürekli uygulanan yoğun tarımsal işlemler ve sabit kültür bitkisi yetiştiriciliğine bağlanabilir kanısı uyandırmaktadır. Bu nedenle yoğun tarımsal uygulamalar sonucunda yabancı ot florasında belli bir farklılık ortaya çıkabileceği düşünülmektedir (Bükün, 2001).

Geleneksel ve organik bağlarda görülen kışlık yabancı otların rastlanma sıklıklarının karşılaştırılması Şekil 4'te görülmektedir. Organik ve geleneksel bağlarda kışlık yabancı otlarda sıra arasında rastlanma sıklığı en yüksek olan tür her iki yöntemde de $S$. media (\% 56-47.4) olmuştur. Bunu organik bağlarda $M$. officinalis (\% 54.6), gelenekselde ise M. chamomilla (\% 42.3) izlemiştir. Çok yıllık ve mücadelesi güç olan yabancı otlardan Conv. arvensis' in de gerek organik gerekse geleneksel bağlarda rastlanma sıklıklarının yüksek (\% 47-40) olduğu görülmektedir.

Sıra üzeri kışlık yabancı otlarda en sık rastlanan yabancı ot organik bağlarda M. chamomilla (\% 54.3) olurken geleneksel bağlarda $H$. murinum (\% 42.8) olmuştur. S. oleraceus (\% 47.2) ve $P$. minor (\% 48.4) organikte en sık rastlanan türler arasında yer almıştır. Yine geleneksel bağlarda $C$. arvensis (\% 32.5) ve $P$. minor (\% 30.2) en çok sık rastlanan türler arasında yer almıştır (Şekil 4).

Geleneksel ve organik bağlarda görülen kışlık yabancı otların yoğunluklarının karşılaştırııması Şekil 5' te görülmektedir. Bu grafikte görüleceği gibi geleneksel üretimde sıra arasında Conv. arvensis (11.8 adet/ $\left.\mathrm{m}^{2}\right)^{\prime}$ in en yoğun tür olduğu, organik bağlarda ise bu bitkinin yoğunluğunun yarıya düştüğü dikkati çekmektedir. Yine sıra arasında H. murinumún geleneksel bağlarda yoğunluk bakımından 2. sırada yer almasına karşın, organik bağ yetiştiriciliğinde bu türün görülmediği görülmemektedir. S. media 'nın organik bağlarda sıra arasında yoğun olduğu görülürken $\left(8.9\right.$ adet $\left./ \mathrm{m}^{2}\right)$, gelenekselde düşüş $(5.2$ adet/ $\mathrm{m}^{2}$ ) olduğu görülmüştür. $C$. bursa-pastoris ve $M$. chamomilla' nın organik bağ alanlarında sıra aralarında gelenekselden daha yoğun bulunmuştur.

Bağ alanlarında sıra üzerindeki kışlık yabancı otların yoğunluğu karşılaştırıldığında, H. murinum'un organikte en yoğun olduğu $\left(32.8\right.$ adet/ $\left.\mathrm{m}^{2}\right)$ olduğu, bunu S. media'nın (12.8 adet/ $\left.\mathrm{m}^{2}\right)$ izlediği görülmektedir. Diğer türler ise 6,1 adet/ $\mathrm{m}^{2}$ yoğunluğunun altında kalmıştır (Şekil 5). Sıra üzerinde geleneksel yetiştiricilikte yabancı ot yoğunluğunun düşük olduğu ve bazı türlerin bulunmadığı görülmektedir. 


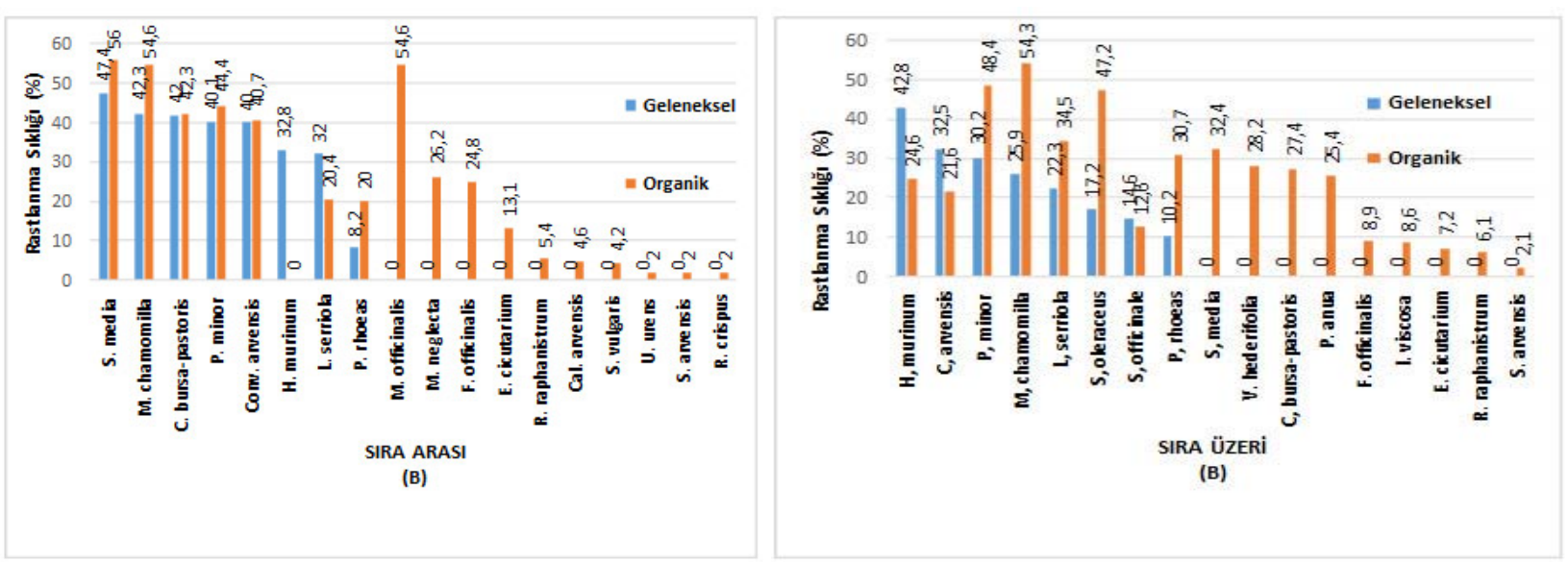

Şekil 4. Geleneksel ve organik bağ alanlarında kışlık yabancı otların sıra arası (A) ve sıra üzeri (B) rastlanma sıklıklarının karşılaştııılması. Figure 4. Comparison of frequency of winter weeds in traditional and organic wineyards as $(A)$ and row (B)
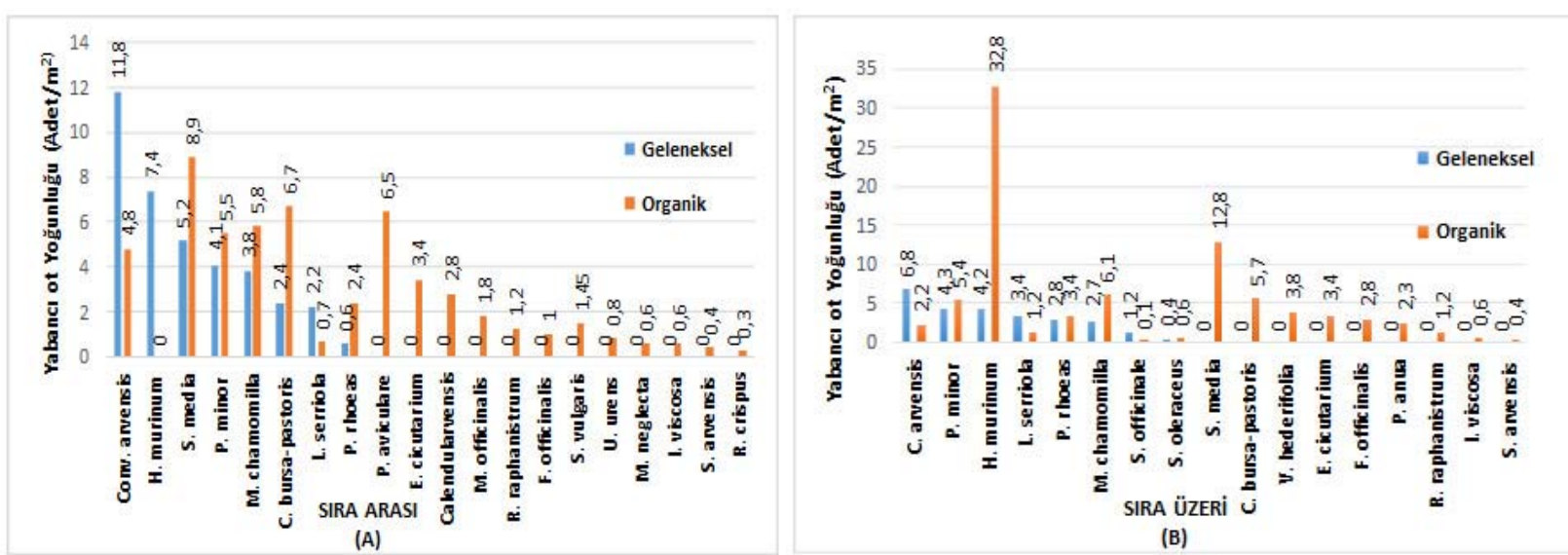

Şekil 5. Geleneksel ve organik bağ alanlarında kışlık yabancı otların sıra arası (A) ve sıra üzeri (B) yoğunluklarının karşılaştırılması.

Figure 5. Comparison of intensity of winter weeds in traditional and organic vineyards as $(A)$ and row (B).

Organik ve geleneksel bağlarda yazlık yabancı ot türleri ve rastlanma sıklıklarının karşılaştııılması Şekil $6^{\prime}$ da görülmektedir. Sıra arasında en çok rastlanan tür, gerek geleneksel gerekse organik bağ alanlarında $C$. dactylon (\% 64.8-51.3) olmuştur. P. australis de her iki yetiştirme şeklinde de en sık rastlanan (\% 46.7-46.4) türler arasında yer almıştır. C. acutum' un sıra arasında geleneksel bağ alanlarında rastlanma sıklığı oldukça yüksek (\% 38.8) görülürken, bu türe organik bağ alanlarında rastlanmamıştır. Organik bağ alanlarında A. retroflexus'a çok sık (\% 52.4) rastlanırken, geleneksel bağ alanlarında bu tür görülmemiştir. $C$. rotundus, $S$. verticillata ve $X$. Strumarium gibi önemli yabancı ot türleri her iki yetiştirme şeklinde yakın rastlanma sıklıklarında görülmüştür (Şekil 6).

Sıra üzerinde yazlık yabancı otlardan en çok rastlanan tür yine $C$. dactylon olmuştur. Bunu gerek organik gerekse geleneksel bağ yetiştiriciliğinde $C$. acutum, $P$. australis, $S$. verticillata, ve $C$. rotundus izlemiştir. C. albumúun organik bağ alanlarında rastlanma sıklığı (\% 26.8) geleneksel bağ alanlarında (\% 9.8) daha yüksek bulunmuştur. Sıra arasında olduğu gibi sıra üzerinde de $S$. halepense' ye sadece organik bağ alanlarında rastlanmıştır (Şekil 6).

Geleneksel ve organik bağ alanlarında yaz döneminde görülen türlerin yoğunluklarının karşılaştırılması Şekil 7'de görülmektedir. Bağlarda yaz döneminde sıra arasında geleneksel bağ alanlarında 8 tür, organik bağ alanlarında 12 tür görülmüştür. Her iki yetiştirme şeklinde de çok yıllık ve mücadelesi zor olan C. dactylon $\left(13,4-8,6\right.$ adet $\left./ \mathrm{m}^{2}\right)$ en yoğun tür olmuştur. Herbisitlerle kontrolü güç olan $P$. australis sıra arasında geleneksel bağ alanlarında $\left(9.4 \mathrm{adet} / \mathrm{m}^{2}\right)$ yoğunlukta iken organik bağ alanlarında $\left(6.7\right.$ adet $\left./ \mathrm{m}^{2}\right)$ daha az 
yoğunlukta olmuştur. C. Rotundus sıra arasında geleneksel bağ alanlarıda $\left(5.8\right.$ adet $\left./ \mathrm{m}^{2}\right)$, organikten (8.4 adet $/ \mathrm{m}^{2}$ ) daha düşük yoğunlukta bulunmuştur. Bu sonucu kullanılan total herbisitlerin etkisine atfedilebilir. Tek yıllık $S$. verticillata organik bağ alanlarında geleneksel bağ alanlarına göre daha yüksek yoğunluk göstermiştir. $P$. oleracea, $A$. retroflexus ve $C$. album organik bağlarda oldukça yoğun görülürken, geleneksel bağlarda ya hiç görülmemiş veya düşük yoğunluk göstermiştir (Şekil 7). Yazlık yabancı otların sıra üzerindeki yoğunluklarının karşılaştırılması Şekil 7'de görülmektedir. Sıra üzerinde gerek organik bağ yetiştiriciliğinde (32.4 adet $\left./ \mathrm{m}^{2}\right)$ gerekse geleneksel bağ yetiştiriciliğinde $\left(17.6 \mathrm{adet} / \mathrm{m}^{2}\right) \quad$ C. dactylon ún yoğunluğu dikkat çekmektedir. C. rotundus geleneksel bağ alanlarında (10.6 adet $/ \mathrm{m}^{2}$ ) organik bağ alanlarına 3.4 adet $/ \mathrm{m}^{2}$ ) göre yaklaşık 3 katı daha fazla yoğunluk göstermiştir. $P$. olereceae ve $X$. strumarium organik ve geleneksel bağ alanlarında sıra üzerinde görülmemiştir. S. halapense organik bağ alanarında sıra üzerinde belli yoğunlukta $\left(2.5 \mathrm{adet} / \mathrm{m}^{2}\right)$ görülmüş, geleneksel bağ alanlarında rastlanmamıştır.

Sonuç olarak geleneksel bağ alanlarında, yabancı ot tür sayısının gerek kış gerekse yaz döneminde organik bağ alanlarına göre az olduğu, ancak mücadelesi güç olan türlerin yoğunluklarının ve rastlanma sıklıklarının yüksek olduğu dikkat çekmektedir. Sonuç kullanılan herbisitlerin yabancı ot türlerini baskılanmasına ve diğer türlerin ön plana çıkmasına neden olabilir. Organik bağlarda ise özellikle kış döneminde tür zenginliği dikkat çekmektedir. Bu durum organik yetiştiriciliğin doğal dengeyi koruması açısından da önemini ortaya koymaktadır.
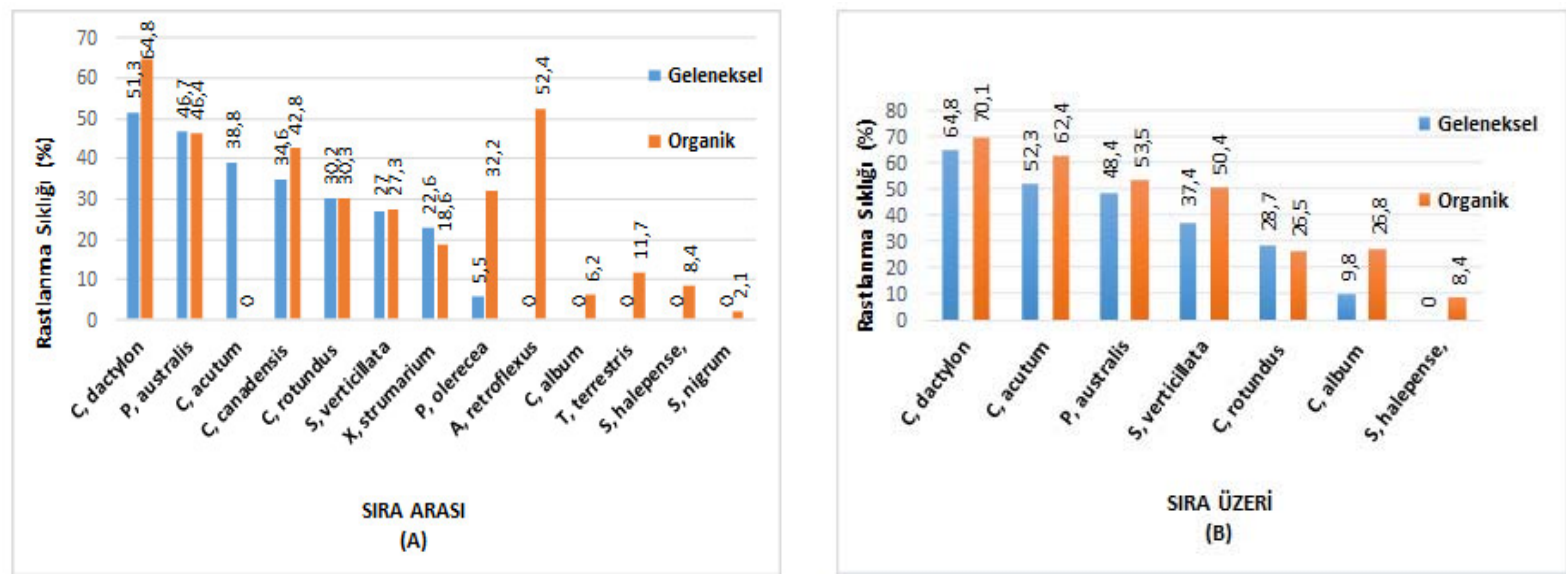

Şekil 6. Geleneksel ve organik bağ alanlarında yazlık yabancı otların sıra arası (A) ve sıra üzeri (B) rastlanma sıkıklarının karşılaştııılması. Figure 6. Comparison of frequency of summer weeds in traditional and organic vineyards as ( $A$ ) and row (B)
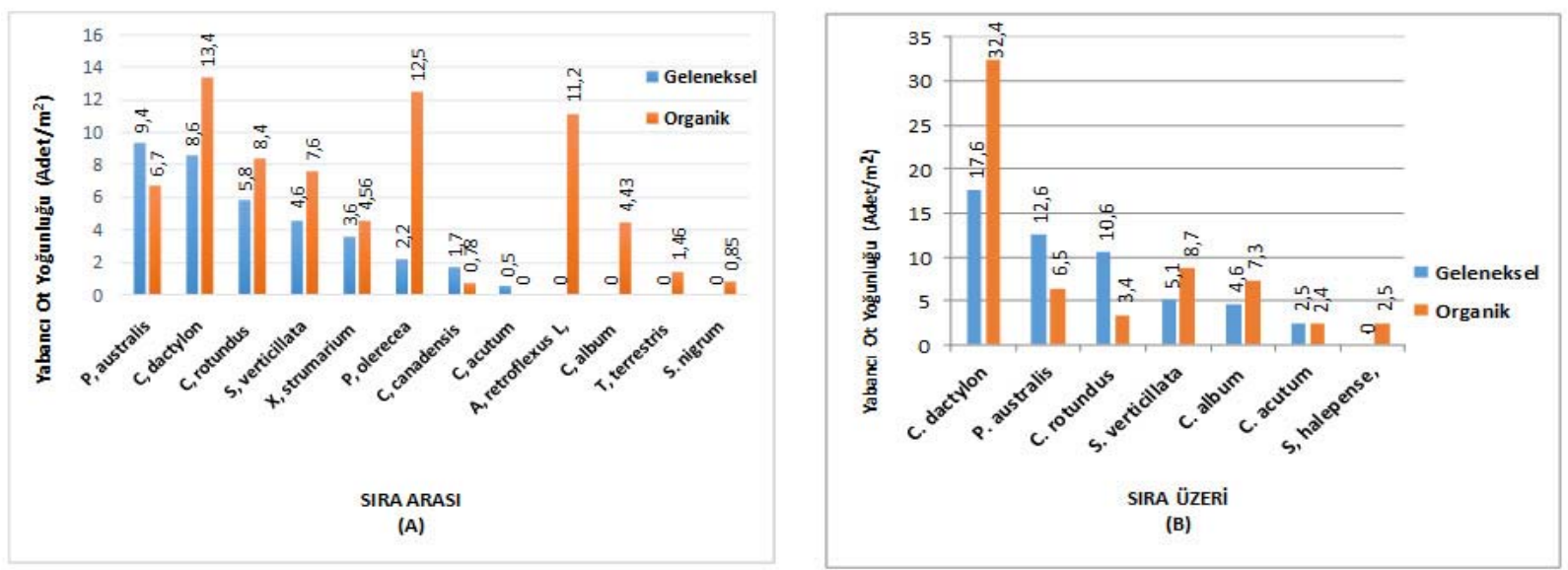

Şekil7. Geleneksel ve organik bağ alanlarında yazlık yabancı otların sıra arası (A) ve sıra üzeri (B) rastlanma yoğunluklarının karşılaştııılması. Figure 7. Comparison of intensity of summer weeds in traditional and organic vineyards as $(A)$ and row $(B)$. 


\section{KAYNAKLAR}

Aksoy. U. 1999. Dünya'da ve Türkiye’de Ekolojik Tarım. Türkiye 1. Ekolojik Tarım Sempozyumu Bildirileri (21-23 Haziran 1999). s. 3-10. İzmir.

Anonim. 2011. T.C. Manisa Valiliği Çevre Ve Şehircilik İ Müdürlüğü Manisa İ Çevre Durum Raporu [http://www.csb.gov.tr/db/ced/editordosya/manisa_icdr2011.pdf.] Erişim Tarihi: 12.07.1014.

Anonim. 2013a. Food and Agriculture Organization of the United Nations. Production Crops. [http://faostat.fao.org/] Erişim Tarihi: 10.11.2014.

Anonim. 2013b. [http://tuik.gov.tr/] Erişim Tarihi: 18.01.2014.

Anonim. 2014. Manisa Ili Valiliği. [http://www.manisa.gov.tr/default_BO.aspx?content=222] Erişim Tarihi: 15.01.2014.

Barralis, G., Drouhard, H. 1969. Contribution a weed describe in vineyards in Bourgogne in France. Proceeding Compte Rendu la 5 Conference pp. 63-883.

Bora, T. ve Karaca, İ., 1970. Kültür Bitkilerinde Hastalığın ve Zararın Ölçülmesi. Ege Üniversitesi Ziraat Fakültesi. Yardımcı Ders Kitab1, Yayın no: 167, Bornova/Izzmir. 43s.
Bükün. B. 2001. Harran Ovası Pamuk Ekim Alanlarında Sorun Olan Fener Otunun (Phsalis spp.) Ekonomik Zarar Eşiğinin ve Kritik Periyodunun Saptanması. Çukurova Üniversitesi Fen Bilimleri Enstitüsü Doktora Tezi. p.110. Adana.

Cramer. H.H. 1967. Plant protection and world crop production. Pflanzenschutz Nacrichten Bayer 1967. 1. Farben Fabriken Bayer A.G. Leverkusen. p. 524.

Davis, P.H.1965-1988. Flora of Turkey and the East Aegean Islands (11 Cilt). Edinburg University Press, UK

Farkhadi. I.A. 1968.Applications of herbicides in vineyards. Sadovodstvo. (11) 28. Weed Research.. 20 (1): 23.

Racz. J.. K. Siaba. 1971. The allelopathic effect of weeds in the vineyards. Obstbau und Fruchtever Vertung 21(4): 264-268.

Sultanova. M.G. 1967. Composition and dynamics of weed flora in vineyard of the Kirovabad. Kazakzone. Uchen. Zap. Azerb. Agronym Series. 6 (2): 131.

Uluğ. E. 1989. Manisa ve Civarındaki Bağlarda Görülen Yabancı Otlar. Fenolojileri. Yayılış Alanları ve Mücadele İmkanları. Adana Zirai Mücadele Araştırma Enstitüsü. p. 18. Adana. 